\title{
Research of Art Design Talents Cultivation Mechanism in the Context of Creative Industry
}

\author{
Li Weiwei*
}

Arts Department of Yellow River Conservancy Technical Institute, Kaifeng, Henan

\begin{abstract}
With the rapid development of economic globalization, informatization and urbanization, creative industry has become the most glamorous new industry with the greatest potential for development in the 21 st century. In the context of creative cultural industry, the college art and design education are facing opportunities and challenges. This paper attempts to research the art design talent cultivation mechanism and reform direction in the context of creative industry in several aspects, trying to provide some ideas and countermeasures for the development of art design education in the new era.
\end{abstract}

Keywords: Art design;talent cultivation, creative industry.

\section{INTRODUCTION}

In recent years, many countries and regions began to take creative and cultural industry as a strategic and pillar industry. Because of the important and positive impact of creative culture industry on the enhancement of the national and urban comprehensive competitiveness at economic and cultural levels, countries and region have begun to focus on the research of the theory and practice of creative and cultural industry. Colleges and universities are the concentrated place of intellectuals, place of talent cultivation and also the base of disseminating culture, knowledge and ideas. The urgent need for innovative talents provides a broad stage for art and design education, but the traditional art design education is difficult to meet the requirements of the creative industry development if no progress is made. Therefore, it is necessary to reform and adjust the current society development and needs to make it better adapt to and serve the development of creative industry.

\section{RELATIONSHIP BETWEEN CREATIVE INDUS- TRY AND DESIGNERS}

The 17th Party Congress report made clear that, in the present era, culture had gradually become an important source of national cohesion and creativity, an important factor of comprehensive national strength, and a richer cultural life was increasingly desired by the people. The development of creative cultural industry, as the most direct carrier of cultural soft power, will be the new potential economic growth point in more and more regions and cities. With the acceleration of globalization and informatization, the competition between cities and regions are more and more intense. Whether cities and regions can gain the initiatives in the competition consists in the enhancement of their overall strength. The overall strength includes the hard power manifested in economy, technology and finance, and also the soft power showed in culture, art, spiritual value and aesthetic appeal. In the current era of knowledge economy, the position of cultural soft power is more and more apparent.

\subsection{Connotation of Creative Culture}

What is creative culture? The concept of creative industry first appeared in the "British Creative Industry Path File" issued in 1998. The file cleared pointed out the so-called creative industry referred to companies gaining development power from individual creativity, skill and talent, as well as the activities could create potential wealth and job opportunities via the development of intellectual property. Based on the saying of David Thirsby in 1997, the creative industry is featured by three characteristics: first, the creative cultural industry activities will use the "originality" in a certain form in the production process; second, the creative cultural industry activities are deemed as related to the generation and communication of symbolic meaning; third, the products of creative cultural industry are at least the "intellectual property rights" in a certain form. On this basis, we can deduce that, the so-called creative cultural industry is to directly transform the abstract culture into the "fine industry" with high economic value. In other words, it is to integrate the knowledge originality and variability into the culture with rich connotation to play the industrial function through the combination with economic. Apparently, it is the process combining knowledge and intelligence to create output.

\subsection{Quality Required by Outstanding Creative Designers}

Design industry is the most stylish industry with the most extensive need. It requires designers to master the world's most sophisticated equipment and software, understand the latest cultural, scientific and technological information, detect the latest needs of the market and consumers, and be able to effectively integrate visual information, create valu- 
able products earning good reputation and control the market. Talent is the core elements in the development of creative and cultural industries, which directly determines the innovation capacity of the entire creative and cultural company. From the perspective of overseas development experience, the development of creative and cultural industry in all countries mainly benefits from the education and cultivation of creative and cultural talents. China's creative and cultural industry is in urgent need of two talents, namely, managers proficient in creative industry content and good at management, creators full of inspiration and creativity. As the creative and cultural industry is an emerging and multidisciplinary cross-cutting industrial categories, the existing higher education still needs to continues to improve the discipline building and educational method. At the same time of training talents of creative cultural industry, we must also create good, relaxing living conditions and entrepreneurial atmosphere for them.

\section{DIRECTION OF THE ART DESIGN EDUCATION REFORM IN THE CONTEXT OF CREATIVE INDUS- TRY}

\subsection{Scientific Division of Disciplines, Clear Direction of Discipline Development}

Unlike other disciplines, the art and design specialty has its distinctive professional features. As a cultural phenomenon, design is produced and developed in the specific environment. On one hand, the environment limits the space of design activities; on the other hand, it provides stage for design art. In the context of creative and cultural industries, the teaching of art design must comply with the development of times, rather than be confined to the traditional design disciplines. In the "Introduction to Design", Yin Dingbang described "Modern design is a unique discipline featured by material and culture......design is associated with the specific social material production and technology, which grants material properties to the design". Finite traditional art and design disciplines confined the crossing and integration between design and other disciplines to some extent, thus developing towards a broader field by adapting to the needs of society. Currently, the teaching of design has not made systematic discipline classification on some new design activities, and these emerging activities are closely related to creative industries. For example, the design of multi-media and tourism products shall enjoy rapid development along with technology progress and social demand, but actually such disciplines have not yet appeared in the teaching of art design so far. Even though some colleges and universities have opened such courses, but they are not regarded as a systematic discipline, but mostly mentioned in other courses as a design phenomenon.

Development of design art must adapt to the needs of society. Art design teaching shall continue to adjust and reform according to scientific development and social needs at any time, so as to cultivate the talents required by the fast developing creative industry. In addition, the education institutes shall make full use of the geographical advantages to open design specialties based on local features. For example, Jingdezhen opened the ceramic design specialty by utilizing the advantages of porcelain capital. The geographical advan- tages are very helpful to the specialty development, and enable the long Chinese tradition and culture to be inherited and carried forward.

\subsection{Work Integrated Learning, Focus on the Training of Practical Talents}

Unlike the pure art disciplines, art design disciplines have distinctive teaching, scientific research and production integration. Designer will eventually serve the community, so they shall not be in extreme arrogance and show no interest in others' matters, but advocate both individuality and team work. They shall have aesthetic modeling capability, be able to adapt to market environment and withstand market test. Only in this way, they can integrate human resources in the operation of creative industry to form concerted efforts and eventually promote the creative project towards success.

In fact, the work-integrated learning art design teaching mode was established in the State Bauhaus Institute nearly a century ago. As the world's first college exclusively established for the development of design education, the teaching ideas founded by Bauhaus have an important impact on the flat design in modern world. Different from the period of Bauhaus, art design discipline has increasingly distinctive features of crossing and blending with natural sciences and humanities, and becomes the integration of multidisciplinary knowledge. As a result, conventional classroom teaching cannot meet the actual needs. In addition to the teaching of professional theory courses in curriculum setting, the proportion of teaching practice shall be increased. Under certain conditions, teachers may lead students into the community to complete the professional courses in the practical environment. Take the art design teaching of our institute as an example, to ensure the implementation of practical teaching, the institute has set collaboration with the surrounding design institutes to establish the base for off-campus practice and industry-academy cooperation. Production internship and graduation design uses the way of internships. In this way, students participate in the project R \& D design, construction and management in the identity of designers in the collaboration units, thereby learning design in work and working in design. Accordingly, students are able to quickly adapt to the practical work related to the specialty after graduation. Of course, too much emphasis on the participation in business or excessive pursuit of economic benefits while ignoring theoretical teaching and academic research is also adverse to the long-term discipline development. Only focus on the working, learning and research as a whole to achieve coordinated development is the guarantee of discipline development and transformation of knowledge into practical productive forces.

\subsection{Enrich Professional Teaching Model, Improve Aca- demic Training Mechanism}

Art design education cannot just be satisfied with the basic design method and vocational skills, but shall consider the comprehensive training of talents in long-term perspective of sustainable development. Strengthen design education by various education links and disciplines to cultivate highquality designers. In the teaching, break the single teaching method to mobilize the initiative and enthusiasm of students. 
For example, in the current creative industry background, artistic designing education of colleges and universities shall boldly attempt the market experimental mode from design to terminal market. Currently, the market's major consumers group consists of post $80 \mathrm{~s}$ and post $90 \mathrm{~s}$. The information contacted by the consumers, received ideas are more in line with international standards. Therefore, traditional products and consumption patterns do not have too much appeal to them. It can be seen from the popularity of iphone series products that they are more concerned about fashion, taste, functionality and other design factors, and pay more attention to culture and life experience at the same time of product consumption. Therefore, it is difficult for today's companies to survive by solely relying on product quality. Despite of high quality, the previous mobile phone giant NOKIA lost its market share due to the negligence of changes in external market environment and user demand. Companies can only win and guide the market by closely following the market, emphasizing consumer experience and relying originality and unique humanities. As the cradle of talents, colleges and universities shall boldly combine with the business model of market experiment in the context of creative industry to make the design better close to the market and consumer, thus realizing the value of design. Only in such ideas of "great culture", "grand design", designers with cultural connotation and potential can be cultivated and professionals and inter-disciplinary talents can be trained to meet the needs of industrial and social development.

\subsection{Strengthen Academic Exchange of Art Design Edu- cation}

In addition to training design talents, the art design education of higher education shall be also be the pioneer of design theory and consciousness, which can drive the design by creative ideas and thinking, boost the consumption market rather than lag behind the market. Therefore, the training and broadening of student creative thinking shall be taken as a major orientation of education reform in art design teaching to encourage the play of creativity. In the new information era, we shall not only have the teaching of design courses, but shall bring the theory and practical experience of design management and market application mode to students by various academic exchange activities between schools, school and industry, thus effectively expand the space for creative thinking, inspire the update of creative thinking. The expansion of academic interaction shall target at the most cutting-edge information, make new attempt and breakthrough in context and form, so as to keep up with the times. For example, the Kaiyuan - Online Life-National Design Education and Design Seminar Education Committee
Annual Meeting hosted by Henan University in 2014, there were symposiums on design workplace and design ecology. Corporate design directors were invited in the discussion of the industry development trend and the business model of online and offline operation. In addition, students and teachers learned the current domestic industry design level and obtained the new industry information from a series of exhibitions, talks and discussions. This academic exchange will undoubtedly inject fresh blood to the teaching of art design, broaden the students' creative thinking and inspire their creative enthusiasm.

\section{CONCLUSION}

In short, with the development of creative and cultural industry and the continuous influence from the new generation of consumers, demand for creative talents is increasingly prominent. At the same time, companies are faced with the challenge of constant product upgrades by means of creative ideas, product design, branding, market segmentation and cross-border cooperation. In this situation, art and design education should also adjust the direction of reform, accelerate the pace of reform, constantly enhance the quality of art design education, make all-round improvement of higher education quality and talent cultivation quality, strengthen social services, optimize the structure and show characteristics to allow the students serve the market and community in real sense.

\section{CONFLICT OF INTEREST}

The author confirms that this article content has no conflict of interest.

\section{ACKNOWLEDGEMENTS}

Declared none.

\section{REFERENCES}

[1] Yin Dingbang, Introduction to Design,Hunan Science and Technology Press, October, 2004.

[2] Jiang Weiwei, Key and Countermeasures of China's Industrial Structure Adjustment,Journal of Tianjin Trade Union Administrator's College, March, 2007

[3] Chen Yu, Exploration of the Practical Mode of Art Design Education Reform in the Context of Creative Industry,Academic Exploration, August, 2013.

[4] Gao Zhiqiang, et. al, Rethinking on the Art Design Education Development in the Horizon of Creative Industry,Hundred Schools in Art, May, 2012.

[5] Hu Qinbao, Core Values of Creative and Cultural Industry, Guangzhou Radio \& TV University Journal, February, 2011. 